\title{
PARAMETRIC STUDY OF A LOW COST PNEUMATIC SYSTEM CONTROLLED BY ON/OFF SOLENOID VALVES
}

\author{
Moataz A. Youssry ${ }^{1}$, Wael M. Elmayyah ${ }^{2}$, Mohamed H. Mabrouk ${ }^{3}$, Hussein M. Mahgoub ${ }^{4}$ \\ ${ }^{1}$ Mechanical Equipment Department, M.T.C., Cairo, Egypt. \\ ${ }^{2}$ Printing Engineering Department, M.T.C., Cairo, Egypt. \\ ${ }^{3}$ Mechanical Equipment Department, M.T.C., Cairo, Egypt. \\ ${ }^{4}$ Mechanical Equipment Department, M.T.C., Cairo, Egypt.
}

\begin{abstract}
Expensive proportional valves are dominantly used in pneumatic positioning systems even with low demanding accuracy positioning tasks, which deprive pneumatic systems from its economical advantages. Thereby, using low cost on/off solenoid valves instead of proportional valves has been a topic of research in the last decades. In this paper, a parametric study is conducted to investigate the effect of using low-cost $3 / 2$ internally pilot on/off solenoid valves to control a double acting cylinder and study the system nonlinear response to on/off and PWM input signal. Matlab ${ }^{\circledR}$ Simscape library is used to model and simulate the system. The model is validated though experimental measurements of the system behavior. The model is used to study and decrease the nonlinear pressure response associated with the cylinder chambers in addition to the evaluation of the dead zone and operating range of the on/off solenoid valve when operated with PWM signal. The results show that using a meter-in flow control and having a near constant cylinder back pressure can reduce the nonlinearity. An orifice of 1 e- $6 \mathrm{~m} 2$ can reduce the pressure variation by $80 \%$ but increase the transient time. Connecting an accumulator with 1 liter volume can result in $50 \%$ reduction in rod side pressure variation. The model has been used to predict the PWM parameters as well. It has been found that the most suitable parameters for this valve are $20 \mathrm{~Hz}$ and duty cycle from 12 to $65 \%$. These results encourage going further with controlling a pneumatic position system using low-cost control valves and a simple controller.
\end{abstract}

Keywords: Pneumatic Control, PWM, On/Off Valves, Simscape, Matlab.

\section{INTRODUCTION}

Pneumatic actuators are widely used in multi positioning tasks applications in a way that requires using of expensive proportional and servo valves. In most cases, these valves are used regardless of the accuracy required for the operation, which eliminates the economical benefits of the designed systems. To decrease the cost of such systems the use of low cost on/off solenoid valves instead of the expensive proportional and servo valves has been a subject of study over the last decades. [12]

In order to develop and improve the performance of any system, modeling and simulation is used as a first step to decrease the amount of experimental work and consequently save money and components life time. Modeling and simulation can be carried out by two methods. The first method is to develop the mathematical equations that describe the system behavior and solve it numerically. Matlab ${ }^{\circledR}$ can be effectively used to solve such dynamic equations [1-5]. The other method is to use software which includes ready-made libraries and blocks that contain the governing equations of the system components. These blocks are connected together to simulate the system behaviour to create the so called physical network modeling of the system. Matlab ${ }^{\circledR}$ Simscape toolbox is an effective toolbox in physical network method because it offers the ease of using physical network method and the huge utility of Matlab ${ }^{\circledR}$ software. Most pneumatic systems researchers use Simscape to model and simulate pressurized tanks [6] , pneumatic cylinders $[7,8]$, and proportional valves [9] but so far it has not been used to model a whole pneumatic system that controlled by on/off solenoid valves.

In this paper, a nonlinear model of a low-cost pneumatic system using physical network modeling method built using Matlab ${ }^{\circledR}$ Simscape toolbox has been developed, which is considered one of the contributions of this paper. The pneumatic system consists of a double acting cylinder controlled by a pair of internally pilot $3 / 2$ direction control valves actuated by electric (on/off) solenoid. The valve is selected to meet low-cost requirement as cheap as $8 \$$. The simscape model includes the time delay of the valve, pneumatic cylinder friction, air compressibility effect and the non-linear airflow through the valves orifices. The experimental test rig description is explained in section 2 of this paper. Section 3 of this paper is devoted to explain the Simscape model of the system. The model is validated by comparing the experimental measurements of the dynamic behaviour of the system with the predicted simulation output, as explained in section 4 . In addition, the valve and system model is validated to work with pulse width modulation (PWM) technique. In section 5, a parametric study is carried out to investigate the system main effective parameters. The parametric study has been used to determine the parameters that can significantly decrease the nonlinearity associated with cylinder chambers pressure. 
The flow control using a meter-in method and the chamber pressure using an accumulator has been investigated. In addition, the parametric study assist determining the effective range of duty cycle corresponding to different PWM input signal to the valve which are considered the key findings of this paper.

\section{EXPERIMENTAL TEST RIG DESCRIPTION}

A representation of the experimental test rig of the system considered in this study is shown in Fig - 1, whereas the pneumatic system schematic diagram is in Fig - 2. The actuator is a double acting cylinder pPD-25-125 ø25 with stroke length $125 \mathrm{~mm}$ and diameter $25 \mathrm{~mm}$. The linear motion of the piston is controlled by two commercial solenoid actuated internally pilot $3 / 2$ pneumatic D.C.V. A linear variable differential transducer (LVDT) WA100 measures the position of the piston. The LVDT has a $80 \mathrm{mV} / \mathrm{V}$ sensitivity and a $4.8 \mathrm{kHz}$ carrier frequency. Two programmable Parker pressure transducers, (SCPSD-01614-15) are used to monitor the pressures in each chamber of the cylinder with output response about $4 \mathrm{~ms}$ and accuracy $\pm 0.5 \%$ from the full scale. Another pressure transducer (PES-110) is used to monitor the supply air pressure with accuracy $\pm 0.5 \%$ from the full scale. A National instrument
(NI) PCI-6033E series data acquisition card (DAQ) is used for acquiring the sensors data with sample rate of $10 \mathrm{kHz}$.

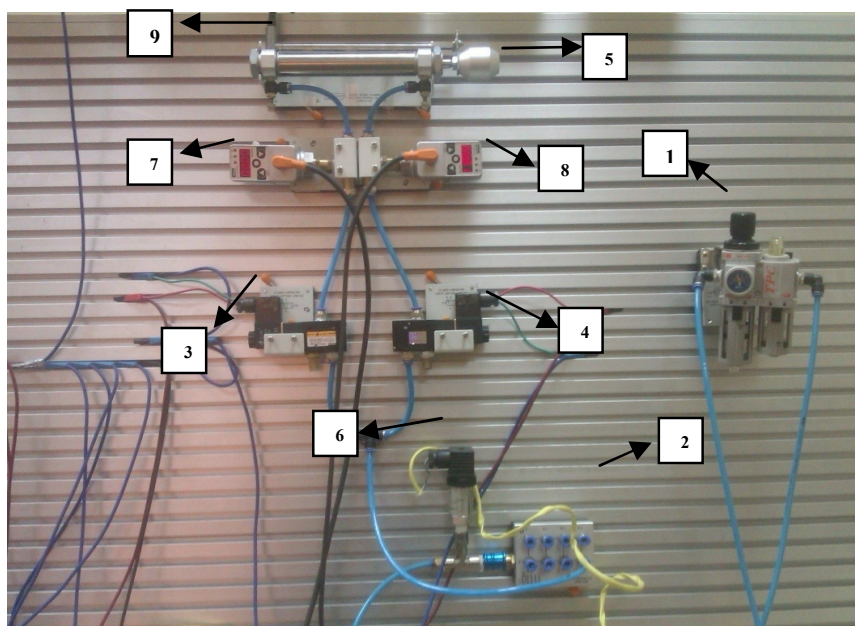

Fig - 1 Pneumatic circuit of the system under study: 1-Air preparation unit, 2-Air distributing unit, 3, 4- 3/2 Solenoid DCV, 5-Double acting pneumatic cylinder, 6-Pressure transducer no.1, 7-Pressure transducer no.2, 8- Pressure transducer no.3, 9-LVDT

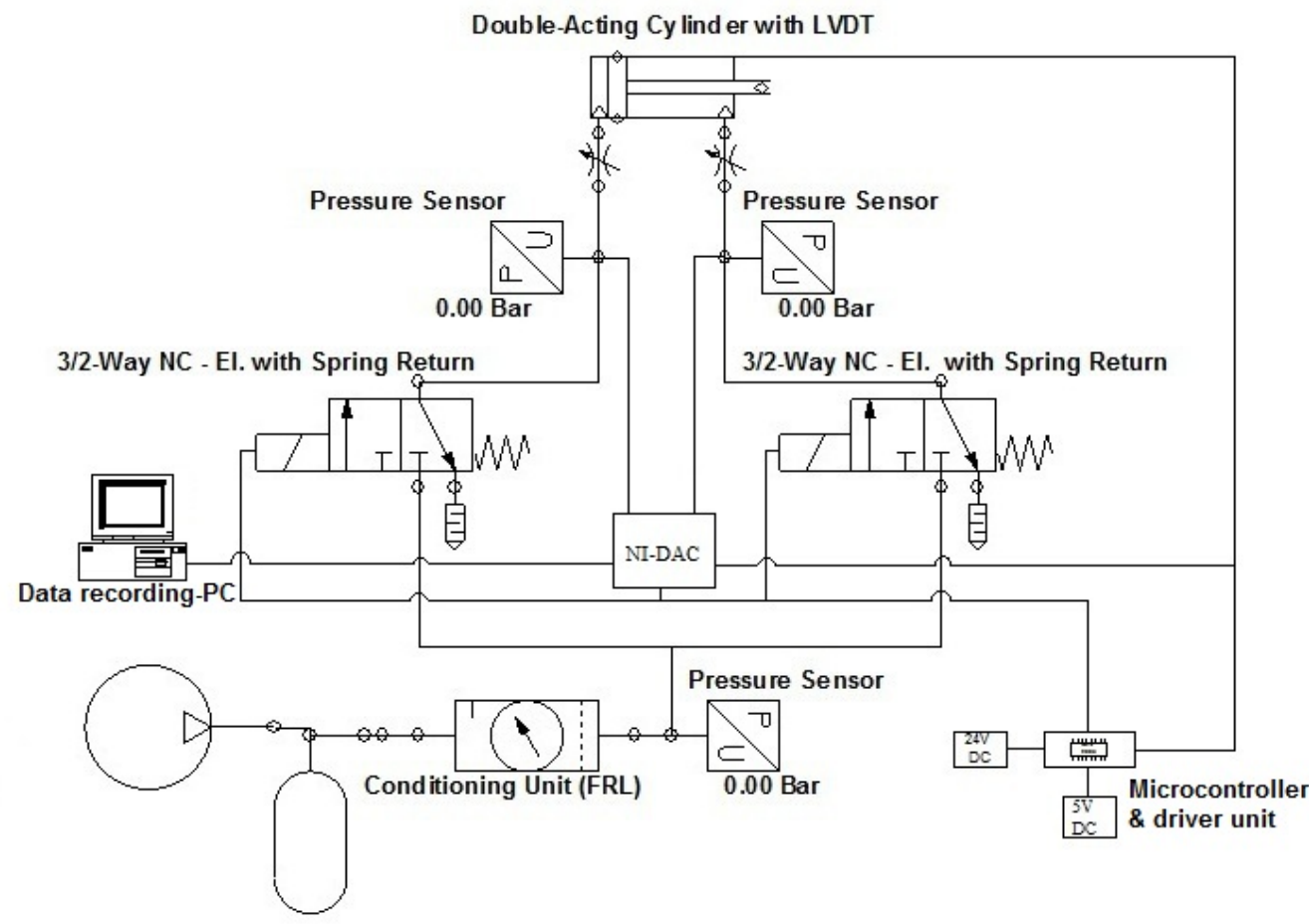

Fig -2 System schematic diagram

\section{PNEUMATIC CIRCUIT SIMSCAPE MODEL}

Simscape provides a Library with ready-made blocks with built in equations for different types of physical components for systems such as mechanical, electrical and hydraulic [6]. A number of subsystems are used here to define the pneumatic system under study where the formation, system input, and output will be mentioned later.

\subsection{Pneumatic 3/2 Directional Control Valve}

The model of the on/off 3/2 DCV under study includes an internally pilot subsystem that controls the state of the valve spool (opened/closed). The valve model is divided into numerous subsystems which are the electrical and magnetic subsystem, the internally pilot subsystem, the mechanical subsystem, and the pneumatic subsystem, as shown in Fig-3. 


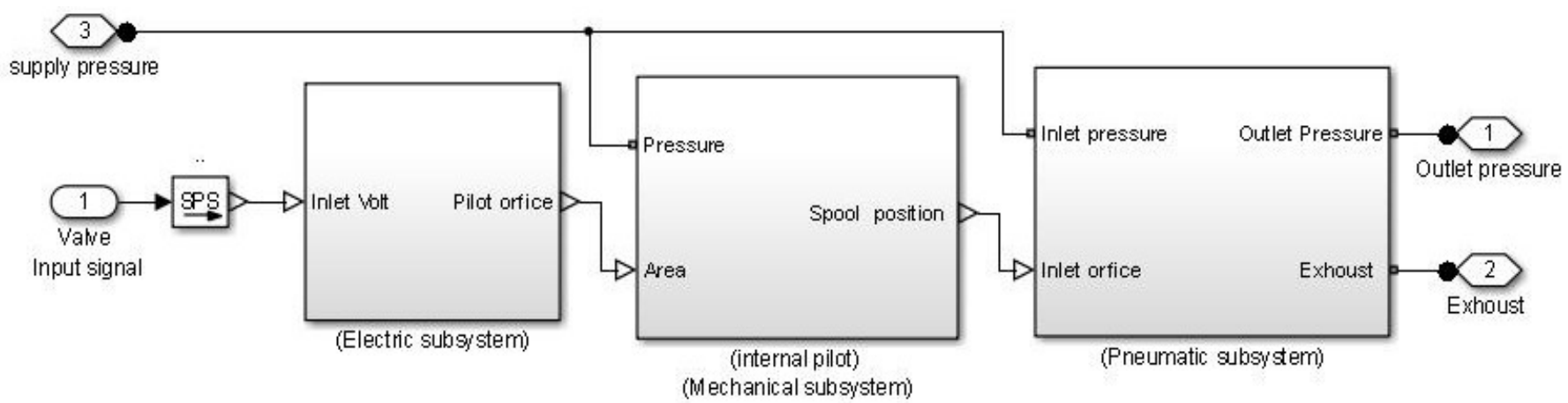

Fig -3 DCV subsystems inlets and outlets

\subsection{Electric and Magnetic Subsystem}

The electric and magnetic subsystem (Model A) of the DCV is represented in Fig - 4, where the input signal (On/Off) connects the power supply to the valve solenoid. The resistor block expresses the coil resistance using Eq.1. The electromechanical converter block provides an interface between the electrical and mechanical translational parts. If the current and voltage through and across the electrical ports are $I$ and $V$, then the force and speed through and across the mechanical ports are $F$ and $v$ where the force $F$ that should overcome the armature mass and compression spring force are expressed in Eq.2. and Eq.3., respectively. The input for this subsystem is the supply voltage value and the output is the armature position. This model was used in previous work [9] but actually it does not meet the actual (measured) solenoid current response. Therefore, in this study another solenoid model (Model B) is proposed depending on the force-stroke characteristics curve of the solenoid as shown in Fig - 5. The inputs is a vector of force values of two points and the corresponding stroke value for these two points, the return spring stiffness, the rated voltage (supply voltage) and rated current (maximum current drawn by the solenoid). A comparison between the two models results is represented in section (4).

$$
V=I \cdot R
$$

Where $R$ is the constant resistance in ohms, and $I$ (A) the current pass through the resistor.

$$
\begin{aligned}
& F=k_{e m} \cdot I \\
& U=k_{e m} \cdot v
\end{aligned}
$$

Where parameter $k_{e m}$ is the Constant of proportionality with equivalent units of $\mathrm{N} / \mathrm{A}$ or $\mathrm{V} /(\mathrm{m} / \mathrm{s})$.

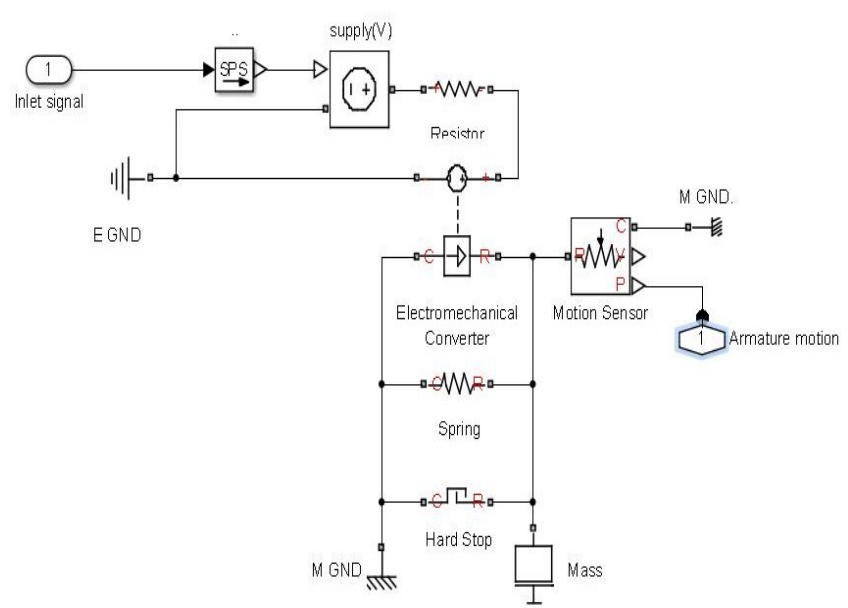

Fig -4 Electric and magnetic subsystem model (Model A)

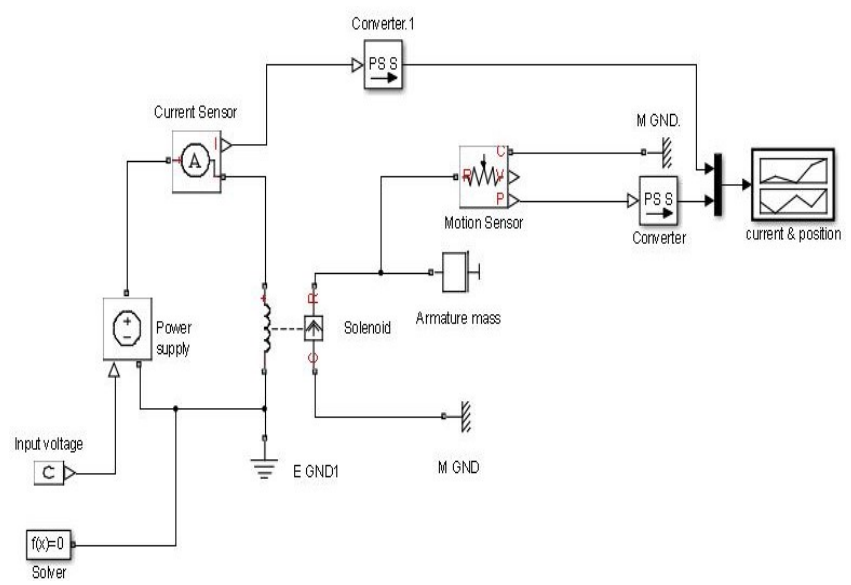

Fig -5 Electric and magnetic subsystem model depending on the force-stroke curve (Model B)

\subsection{Internal Pilot and Mechanical Subsystems}

To understand the operation of the internal pilot and mechanical subsystems the valve is represented by a threedimension CAD model, which is built by Autodesk Inventor ${ }^{\circledR}$ as shown in Fig - 6. The valve in the CAD model in normally closed. The pressurized air enters the valve (large arrow) and passes through internal passage to the armature side. When the armature is pulled up, the pressurized air fills the armature chamber and then pushes the disk (blue) as well as the spool to the left closing the exhaust port and open passage to the pressurized air to the piston side port (Exhaust port). 


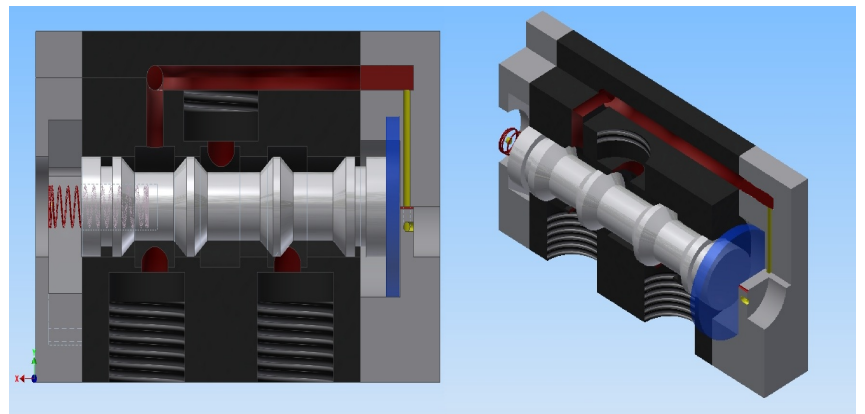

Fig - 6 Valve CAD model
Fig -7 represents the internal pilot and mechanical subsystems simscape model. The pressurized air enters from port 1 to the orifice area, which is controlled by the output of the previous subsystem output (Armature position). The air flows through port A of single acting cylinder that acts as the valve spool and move it against the valves return spring and friction force. Air has been considered as an ideal gas passes through a sharp edge orifice area where no heat flow losses through the orifices as expressed by Eq. (4) -Eq. (6) .The inlet to these sub systems is the supply pressure and armature position and the outlet is the spool position.

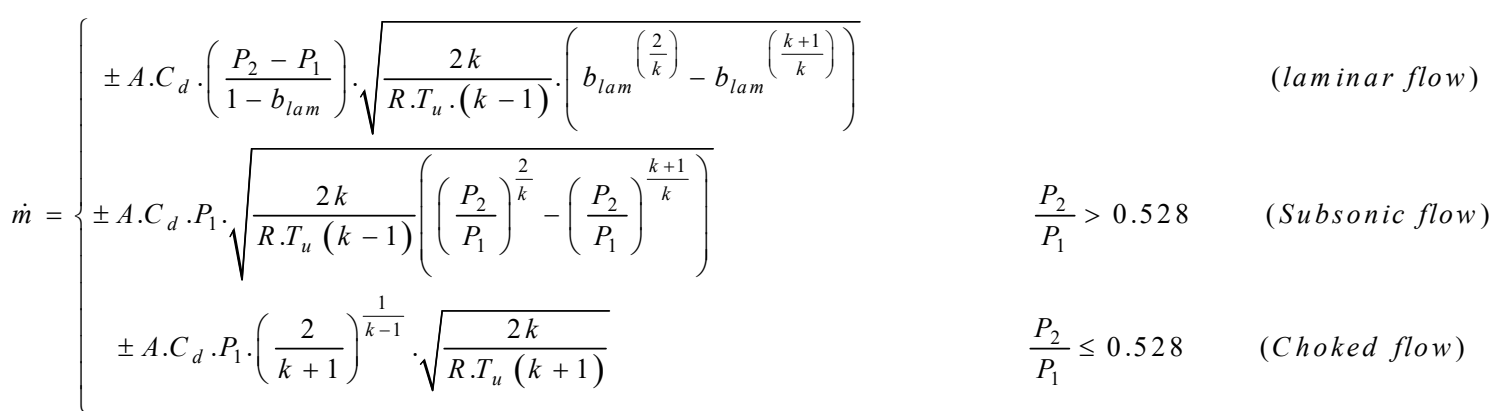

$\mathrm{Q}_{1}=\dot{m} \cdot \mathrm{c}_{\mathrm{p}} \cdot \mathrm{T}_{\mathrm{u}}$

$\mathrm{Q}_{2}=-\dot{m} \cdot \mathrm{c}_{\mathrm{p}} \cdot \mathrm{T}_{\mathrm{u}}$

Where $\dot{m}$ is the mass flow rate $(\mathrm{kg} / \mathrm{s}), A$ is the orifice area (mm2), $C_{d}$ is the discharge coefficient, $P_{1}$ and $P_{2}$ are the upstream and downstream pressure pressures $(\mathrm{Pa}), b_{\text {lam }}$ is the pressure ratio above which a laminar flow exist, $T_{u}$ is the minimum absolute temperature expected in the simulation $(\mathrm{K}), k$ is the air polytropic exponent (1.4), $\mathrm{c}_{\mathrm{p}}$ air specific energy $(\mathrm{Kg} . \mathrm{K} / \mathrm{J})$.

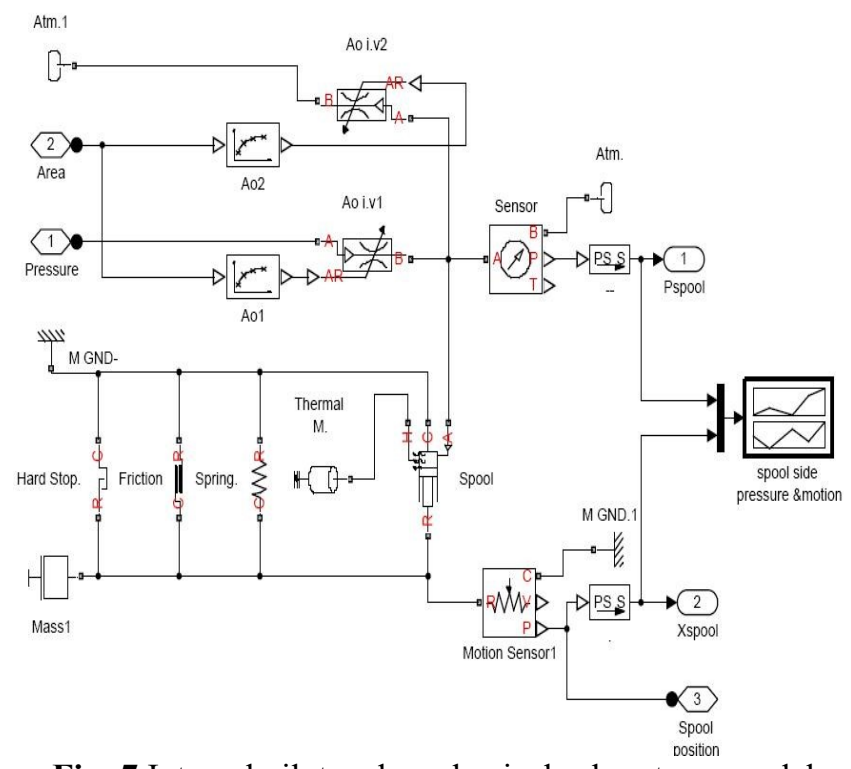

Fig -7 Internal pilot and mechanical subsystems model

\subsection{Pneumatic Subsystem}

The model that is shown in Fig -8 represent the valves inlet and exhaust orifices. The pneumatic subsystem is built using the help of Simscape toolbox for $5 / 3$ pneumatic directional control valve (DCV) [10]. Once the spool is moved, the passage connecting the piston side port and the exhaust port is closed (Ao outlet block), and the pressurized air flows from the inlet port to the piston side port (Ao inlet block) as shown in the figure. The inputs of this subsystem are the pressurized air (compressor block output) and the spool position, which is converted to the orifices area by a lookup tables (Ao3 and Ao4 blocks). The output is the outlet pressurized air flow to the piston.

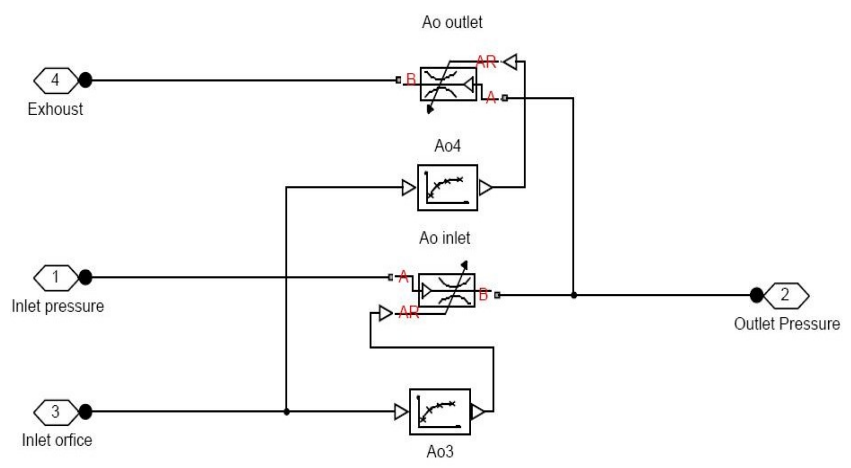

Fig -8 Pneumatic subsystem model

\subsection{Pneumatic Double Acting Cylinder}

The double acting cylinder model design has been guided by the design of the double acting cylinder model Matlab example [11]. A transitional friction block is added to the model to simulate and consider the piston friction forces (static and dynamic friction forces). In addition, pressure sensors has been added show the rate of change in the 
cylinder chambers pressures against the volume change as shown in Fig -9. The cylinder model governing equations is revealed trough eq. 7 to 9 .

1) Mass flow rate equation:

$\dot{m}=\left(\dot{P}-\frac{P \cdot \dot{T}}{T}\right) \cdot\left(\frac{V_{0}+A_{p}\left(x_{0} \pm x_{p}\right)}{R \cdot T}\right)+\frac{P \cdot A_{p} \cdot\left( \pm \dot{x}_{p}\right)}{R \cdot T}$

2) Heat energy equation:

$\dot{Q}=\frac{C_{V}}{R} \cdot \dot{P} \cdot\left(V_{0}+A_{p}\left(x_{0} \pm x_{p}\right)\right)+\frac{C_{p}}{R} \cdot P \cdot A_{p} \cdot\left( \pm \dot{x}_{p}\right)$

3) Force equation

$m_{p} \cdot \ddot{x}=\mp\left(P-P_{\text {atm }}\right) \cdot A_{p}$

Where $\dot{m}$ is the air mass flow rate $(\mathrm{kg} / \mathrm{s}), m_{p}$ is the piston mass $(\mathrm{kg}), \ddot{x}$ is the piston acceleration $(\mathrm{m} / \mathrm{s} 2), A_{p}$ is the piston area $(\mathrm{m} 2), x_{o}$ is the piston initial position $(\mathrm{m}), V_{o}$ is the cylinder dead volume $(\mathrm{m} 3), P$ is the chamber pressure (Pa), $P_{a t m}$ is the atmospheric pressure $(\mathrm{Pa}), T$ the chamber temperature $(\mathrm{K}), x_{p}$ is the piston position $(\mathrm{m}), R$ gas constant $\mathrm{J} /(\mathrm{kg} . \mathrm{K}), C_{p}$ specific heat capacity at constant pressure $\mathrm{J} /(\mathrm{kg} . \mathrm{K}), C_{v}$ specific heat capacity at constant volume $\mathrm{J} /(\mathrm{kg} . \mathrm{K}), F$ and is the force acting on the piston (N).

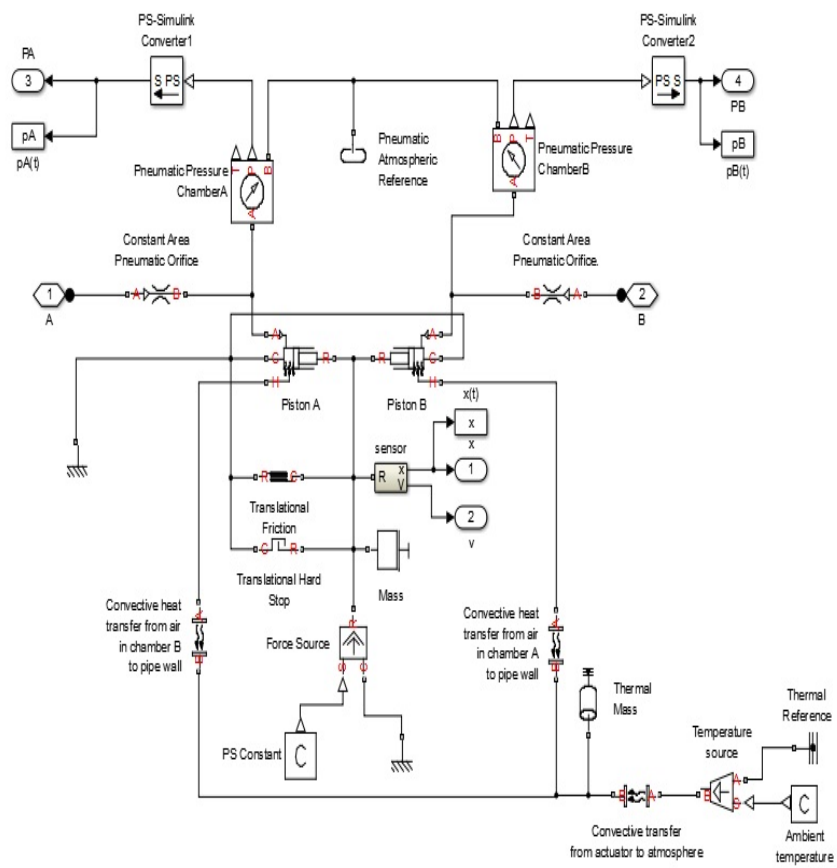

Fig -9 Double acting cylinder model

\section{SIMSCAPE MODEL VALIDATION}

Simscape model is validated by comparing the experimental measurements of the system dynamic behaviour to the predicted one (simulation outputs). Fig -10 represents a comparison among the measured solenoid current, the output current using model A used in previous work [9], and model B presented in this study. The results show that model $\mathrm{B}$ is more accurate and give better prediction of the armature position than model A. Fig -11 illustrates a comparison between predicted values and experimental values of the pressure of the piston chamber versus time at different supply pressures. The experiments are carried out by extending the cylinder at four different supply pressures. The input signal is applied at the same time $(100 \mathrm{~ms})$ as shown in the figure. The figure shows a very small deviation of the simulation result from the experimental measurement.

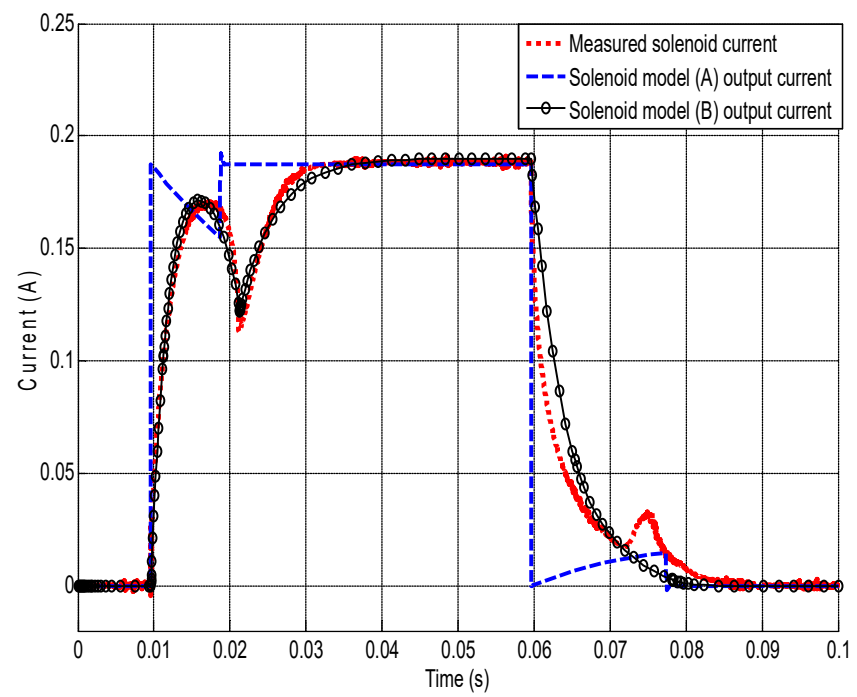

Fig -10 Comparison between the solenoid models current response and the experimentally measured one

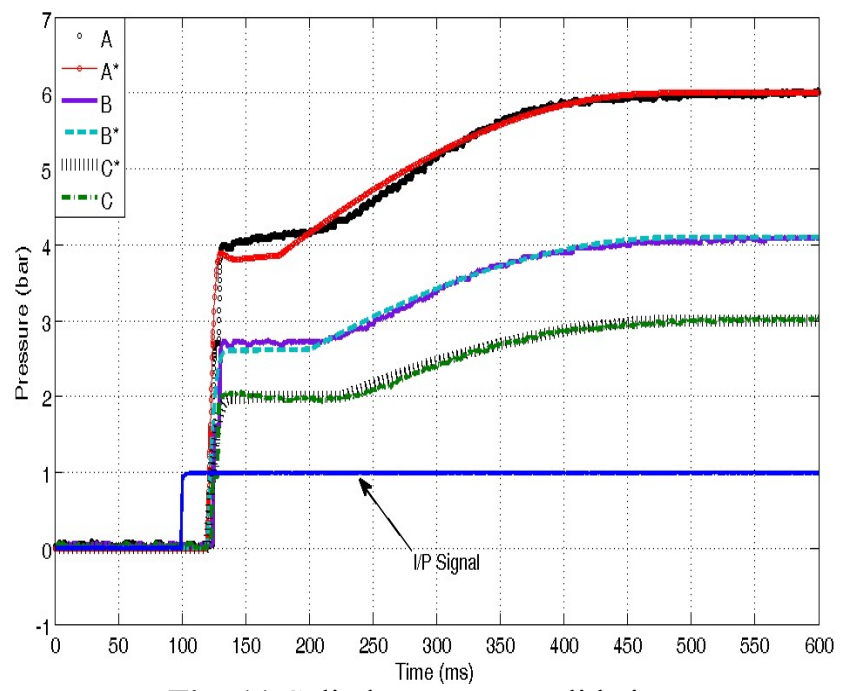

Fig -11 Cylinder pressure validation,

$\mathrm{A}$ is the measured pressure at Ps $6 \mathrm{bar}, \mathrm{A}^{*}$ is the predicted pressure at Ps 6bar, B is the measured pressure at Ps 4bar, $\mathrm{B}^{*}$ is the predicted Ps 6bar,C is the measured pressure at Ps 3 bar, $\mathrm{C}^{*}$ is the predicted pressure at Ps $3 \mathrm{~b}$

Fig -12 illustrates the behavior of the piston when extended using three different supply pressures. The experimental measurements applied to $100 \mathrm{~mm}$ from the full stroke $(125$ $\mathrm{mm}$ ) due to the LVDT measuring range. The simulation results show good agreement with the measured one. 


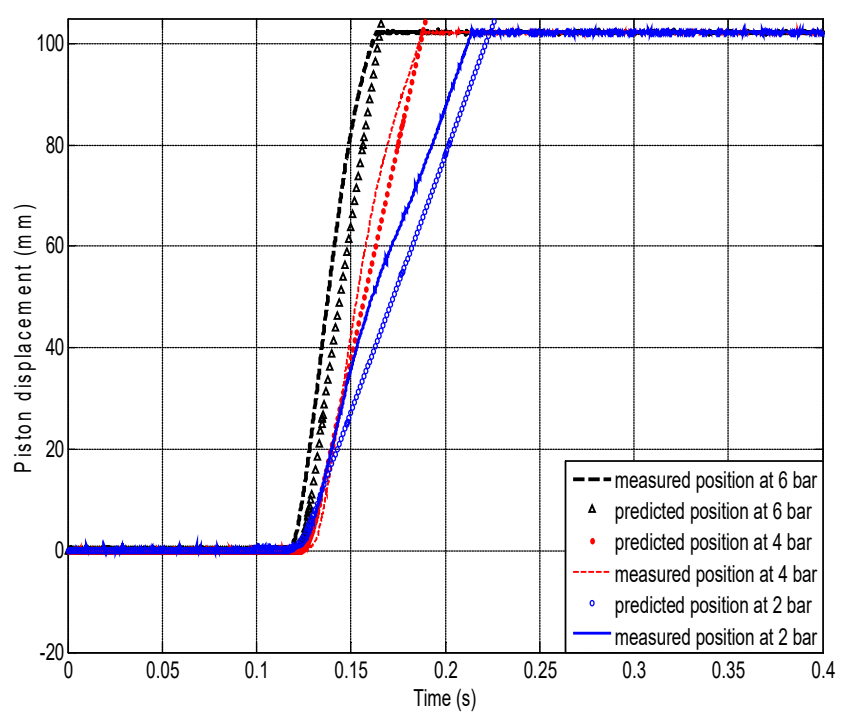

Fig -12 Comparisons between predicted and experimental displacement of the piston versus time at different supply pressure

Generally, pulse width modulation is a common method to operate on/off solenoids. Therefore, the model here is validated to work with pulse width modulation (PWM) applications. The piston is extended and retracted where the $3 / 2$ solenoid DCV is subjected to two different PWM signal frequencies $10 \mathrm{~Hz}, 20 \mathrm{~Hz}$. Each frequency is used with two different duty cycles and then the measured piston displacement is compared with the simulation results for the same input PWM signals as shown in figures from Fig -13 to Fig -16. As shown in the figures there is a good agreement of the predicted and measured data at different PWM schemes.

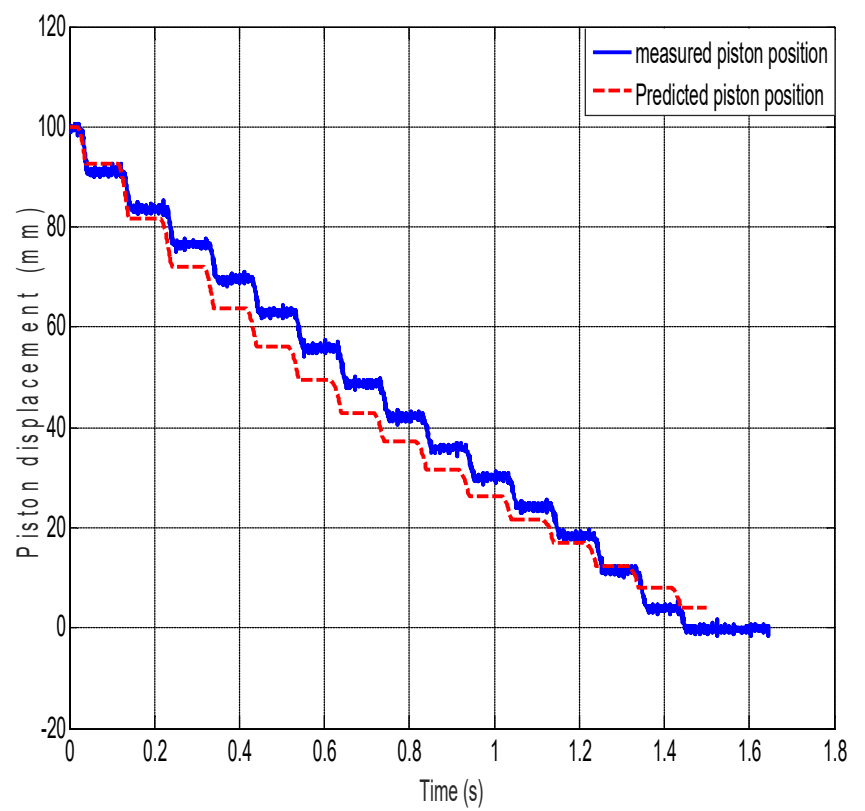

Fig -13 Comparisons between predicted and experimental displacement of the piston versus time when retracting the cylinder using PWM I/P (F=10 Hz, D=20\%, Ps=2bar)

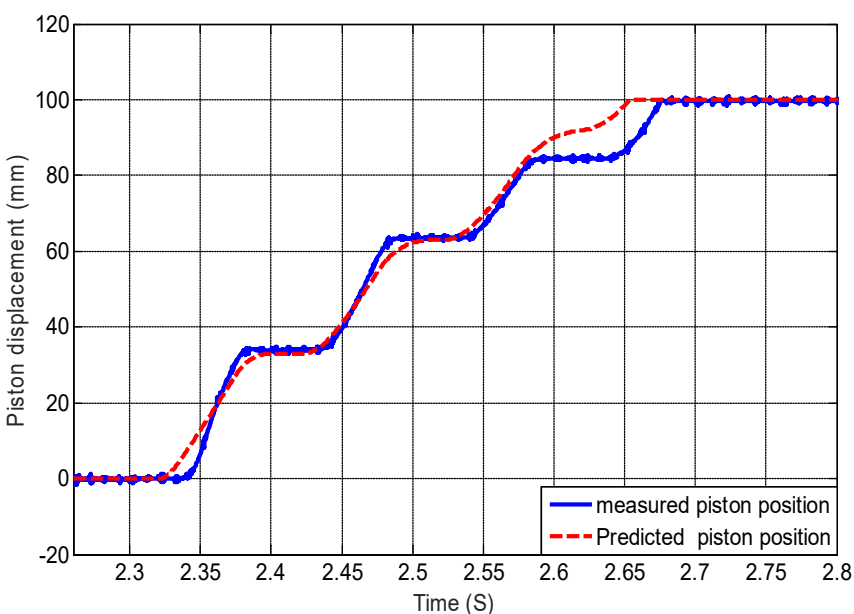

Fig -14 Comparisons between predicted and experimental displacement of the piston versus time when retracting the cylinder using PWM I/P (F=10 Hz, D=50\%, Ps=2bar)

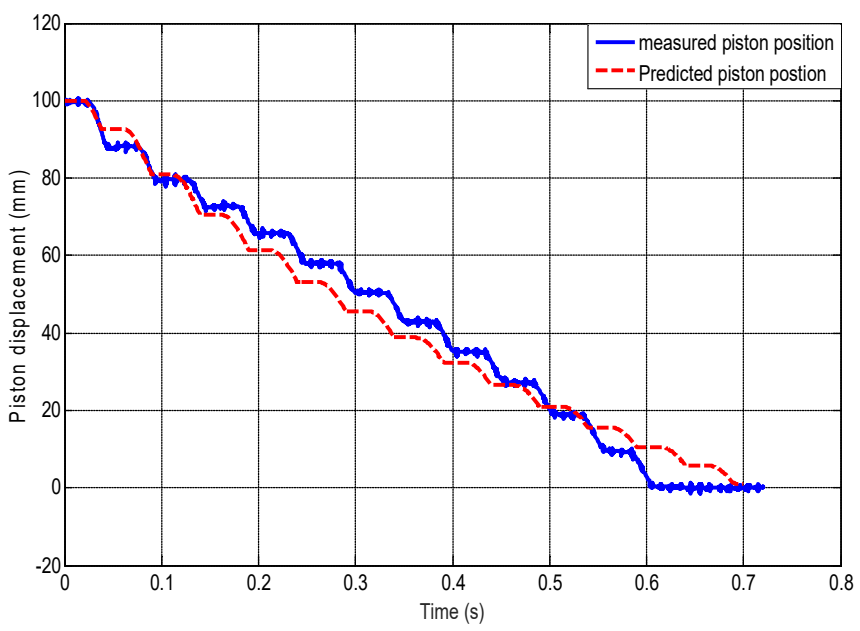

Fig -15 Comparisons between predicted and experimental displacement of the piston versus time when retracting the cylinder using PWM I/P (F=20 Hz, D=40\%, Ps=2bar)

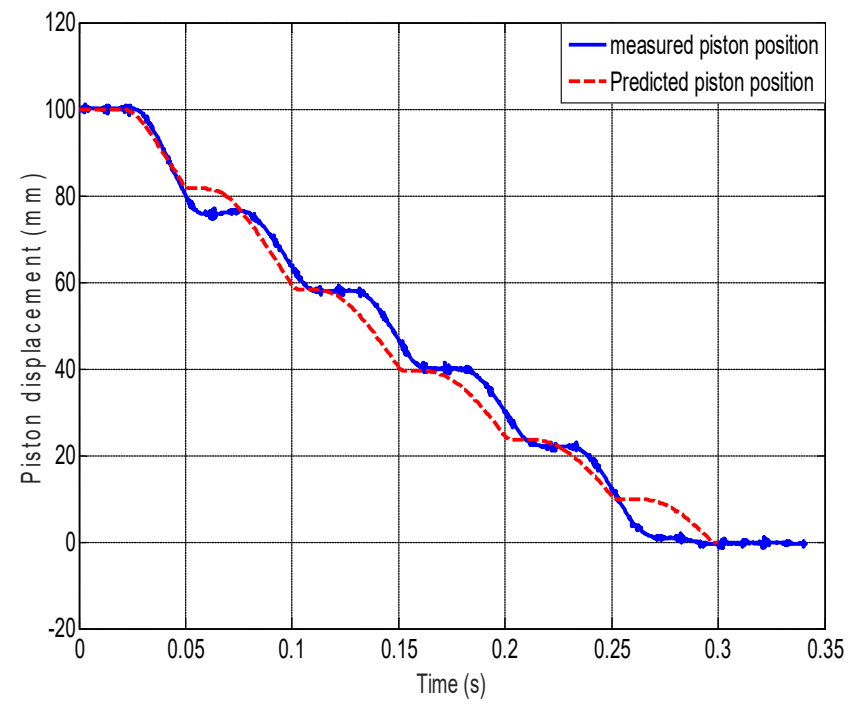

Fig -16 Comparisons between predicted and experimental displacement of the piston versus time when retracting the cylinder using $\mathrm{PWM} \mathrm{I} / \mathrm{P}(\mathrm{F}=20 \mathrm{~Hz}, \mathrm{D}=60 \%$, $\mathrm{Ps}=2 \mathrm{bar})$ 


\section{PARAMETRIC STUDY}

Fig -17 shows the piston side chamber when extending the piston at different supply pressure at same load conditions. While Fig -18 shows the corresponding rod side pressure (backpressure). At these figures the working pressure of the cylinder is not constant however the fixed load condition (no load) which make it harder to control for acceptable position control. It is much easier to control the cylinder if the working pressure depend only the load and the compressibility effect is neutralized. Two main techniques are used to reduce the effect of air compressibility. The first is to control the airflow rate into the cylinders chambers while the second is to maintain a nearly constant backpressure for the piston.

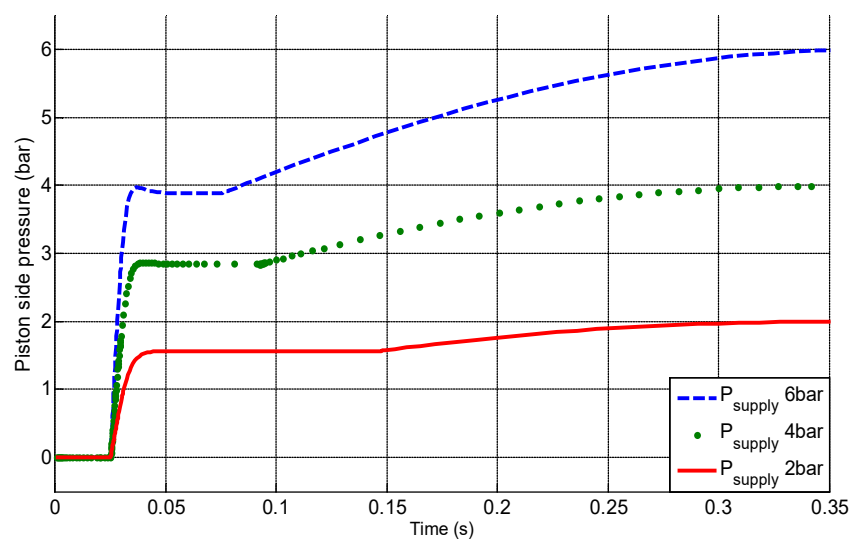

Fig -17 Model output of the piston side pressure when extending the cylinder with different supply pressure

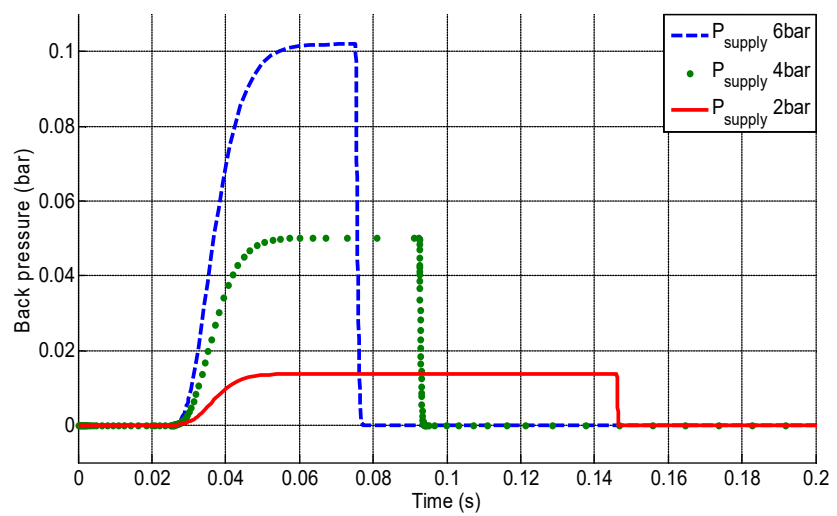

Fig -18 Model output of the rod side pressure when extending the cylinder with different supply pressure

\subsection{Controlling the Air Flow Rate}

In order to reduce the this nonlinear behaviour of the pressure response of the cylinder chambers, some methods may be used. One of them is to use a frictionless cylinder and metering-in the airflow to the cylinder. Meter-in control results in a slow air entry to the cylinder. Consequently then the piston moves with low speed, permits the air in the rod side to flee freely, and can be considered incompressible gas. In this method, for an ideal, frictionless cylinder, the volume of air added to the piston side of the cylinder is assumed to be equal to the volume of air removed from the second chamber [12]. Fig -19 and Fig -20 respectively show the front and backpressure of the cylinder when extending the cylinder with different supply pressure with meter-in flow control. Using a meter-in flow control results in decreasing the pressure variation in the piston side chamber. For example at orifice $1 \mathrm{e}-6 \mathrm{~m} 2$ area and assumed 0.8 discharge coefficient the piston side pressure variation is reduced by $80 \%$. The figures (19 and 20) show a decrease in the cylinder chamber pressure variation while the time travel of the piston is increased by $130 \%$ at pressure ranging from 5 to 8 bar. Fig -21 shows the relation between the piston side pressure variation when extending the piston at different supply pressures (from 5, 6 and 8 bar) and meter in orifice area start from 1e-6 m2. It can be concluded that controlling the flow area by using meter-in control can be efficiently used in applications that require different supply pressure. As reducing the pressure, variation can result in an easier control for the position. However, meter-in control will affect the cylinder speed, which is not suitable for applications that need quick response.

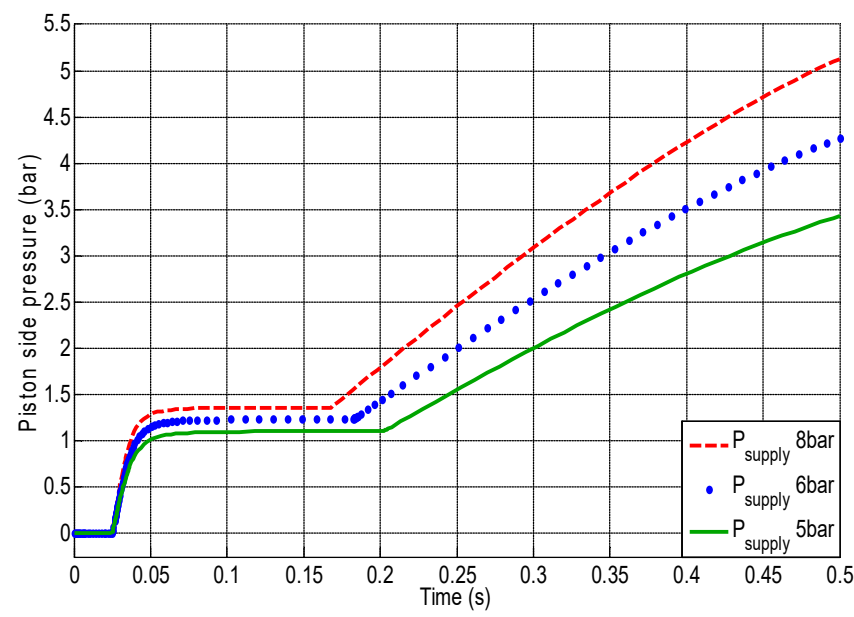

Fig -19 Predicted piston side pressure when extending the cylinder with different supply pressure with meter in flow control

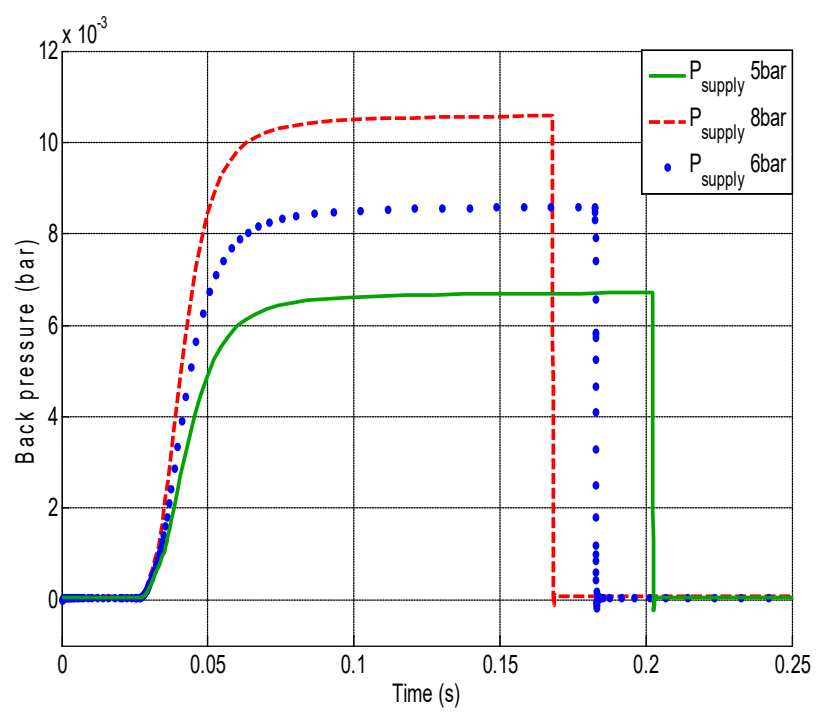

Fig -20 Predicted rod side pressure when extending the cylinder with different supply pressure with meter in flow control 


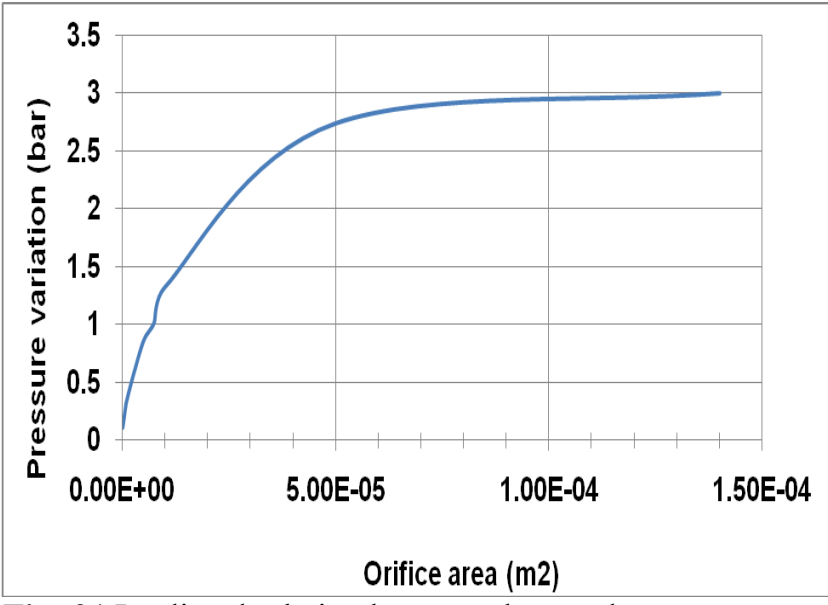

Fig -21 Predicted relation between the steady state pressure variation between 5 and 8 bar and the orifice area of the meter in flow control valve.

\subsection{Controlling the Piston Back Pressure}

the other method to reduce the compressibility effect is to maintain almost constant backpressure which will decrease the nonlinearities associated with the back pressure. This can be achieved by connecting an accumulator to the rod side chamber [13]. For example with connecting an accumulator of volume of $1 \mathrm{~m} 3$ and pressure of 2 bar, the back pressure variation is decreased by $99 \%$ as shown in Fig -22 and Fig -23. While if the accumulator volume is 1liter and its pressure 1 bar, the pressure variation is about $50 \%$. The Figure shows an almost constant backpressure in the cylinder. Fig -24 shows the relation between the backpressure variation and the accumulator volume when the accumulator pressure is 2 bar.

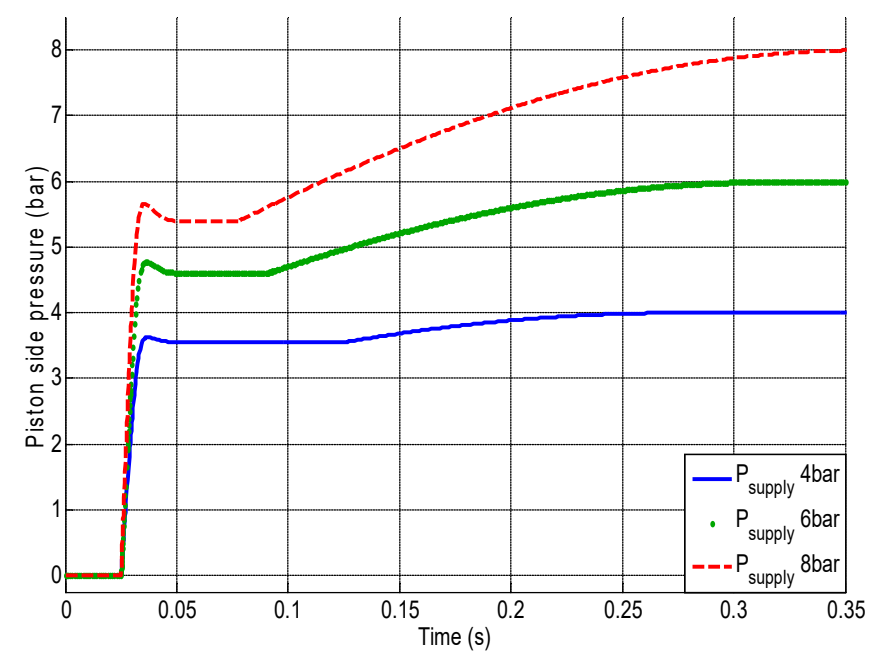

Fig -22 Predicted piston side pressure when extending the cylinder with different supply pressure with accumulator at the cylinder exit.

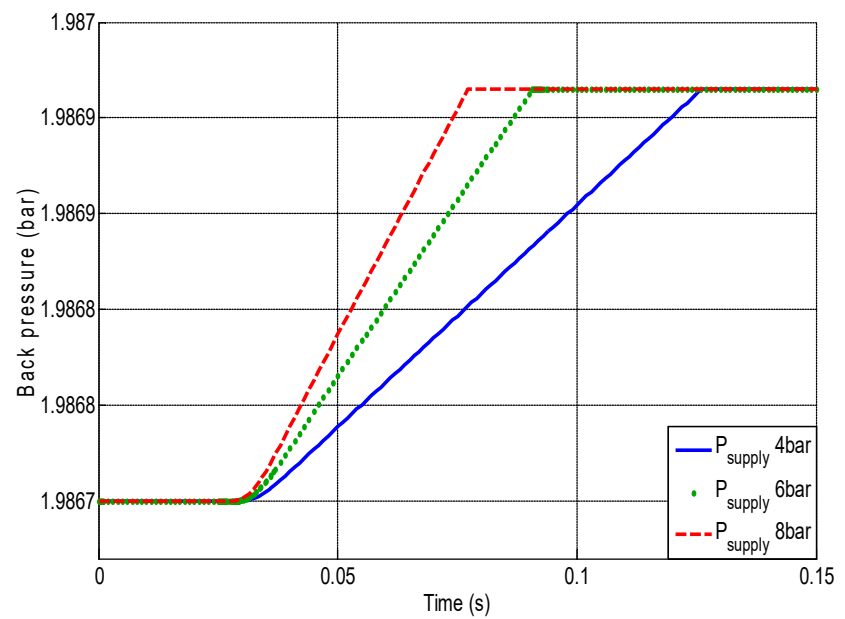

Fig -23 Predicted rod side pressure when extending the cylinder with different supply pressure with accumulator at the cylinder exit.

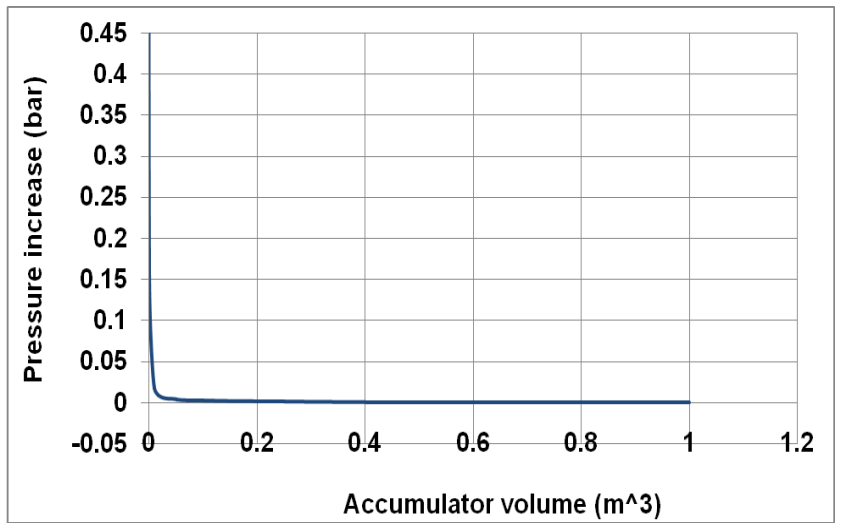

Fig -24 Relation between the Accumulator volume and the backpressure variation

\subsection{Predicting the PWM Parameters}

In order to study the valve model response to PWM operation, a model of the solenoid actuated $3 / 2 \mathrm{DCV}$ connected directly to the pressure transducer; not to the cylinder ports; is created and PWM signal is applied as shown in Fig -25 . The simulation is carried out with different frequencies at different supply pressure values in order to detect the suitable PWM operating frequency and duty cycle working range. The PWM input signal begins from zero \% duty cycle and gradual increment to $100 \%$ duty cycle. Fig - 26 and Fig - 27 respectively show the valve model response to $\mathrm{PWM}$ input (I/P) signal at frequencies 10 and $30 \mathrm{~Hz}$ and supply pressure 4bar. Fig -28 shows the valve model response to PWM I/P signal with frequency 20 $\mathrm{Hz}$ and different supply pressure 4bar, 6 bar. The figures show a dead zone of duty cycle (D) where the valve is not responding to input signal and this dead zone affects by the PWM operating frequency but almost not affected by the change in the supply pressure. Fig - 29 shows the effective duty cycle range corresponding to different applied PWM signal frequencies. From these figures it can be concluded that the effective duty cycle range is from 12 to $65 \mathrm{~Hz}$ while the $20 \mathrm{~Hz}$ gives an effective valve response. 


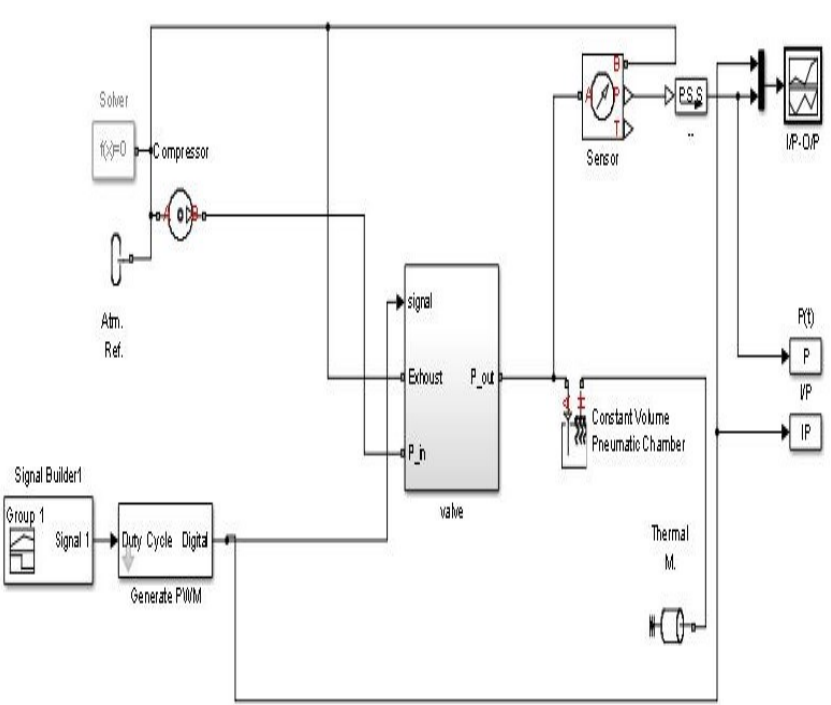

Fig -25 Valve model to test the PWM performance

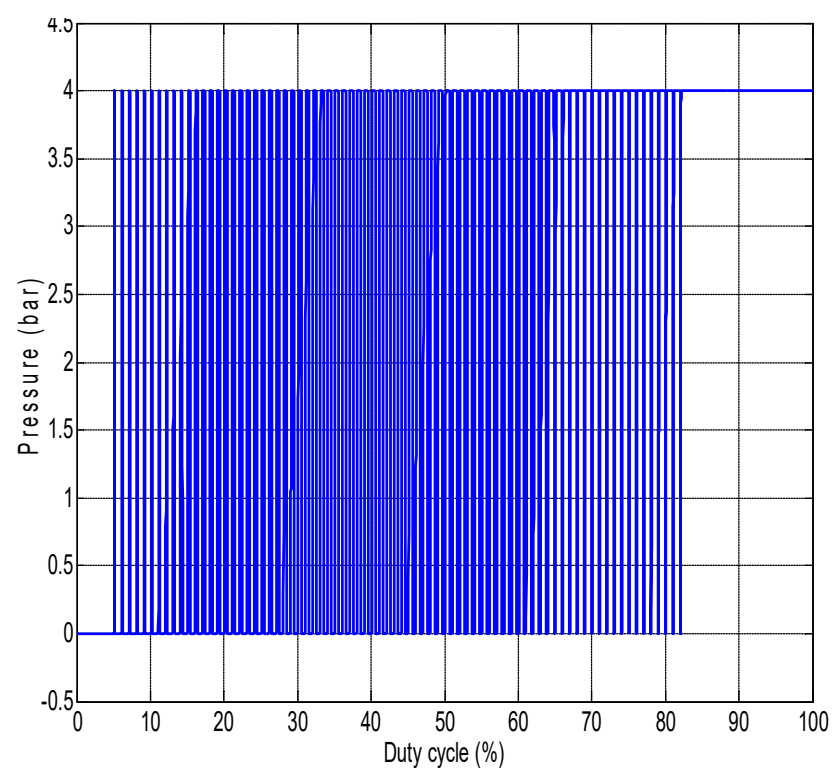

Fig -26 Predicted valve output pressure when operated by PWM frequency $10 \mathrm{~Hz}$ at $4 \mathrm{bar}$

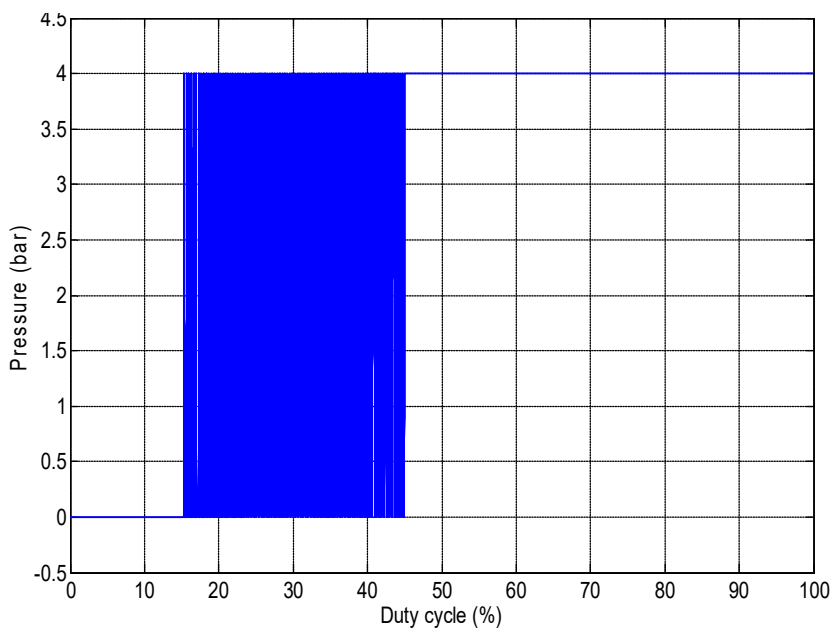

Fig - 27 Predicted valve output pressure when operated by PWM frequency $30 \mathrm{~Hz}$ at $4 \mathrm{bar}$

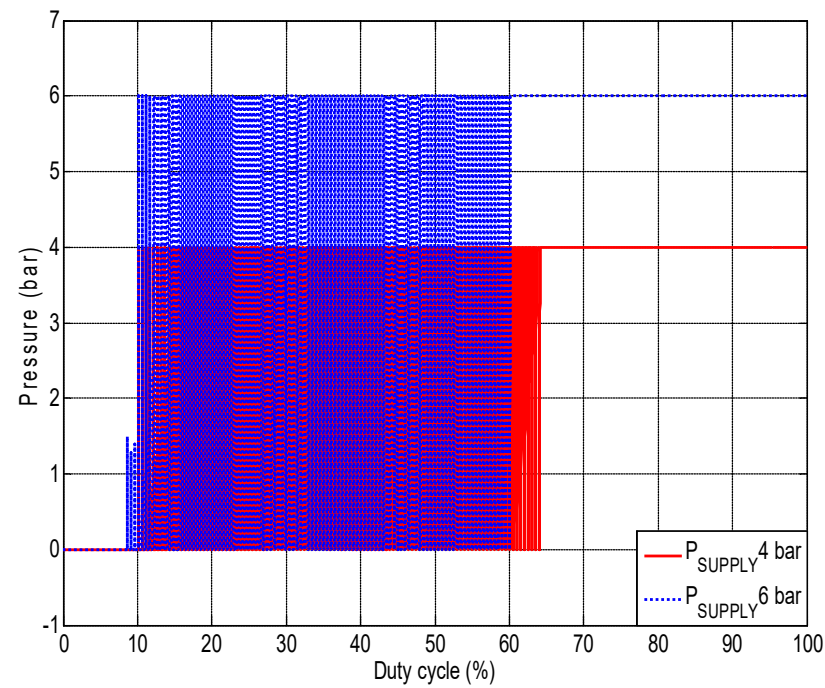

Fig -28 Predicted valve output pressure when operated by PWM frequency $20 \mathrm{~Hz}$ at different supply pressure

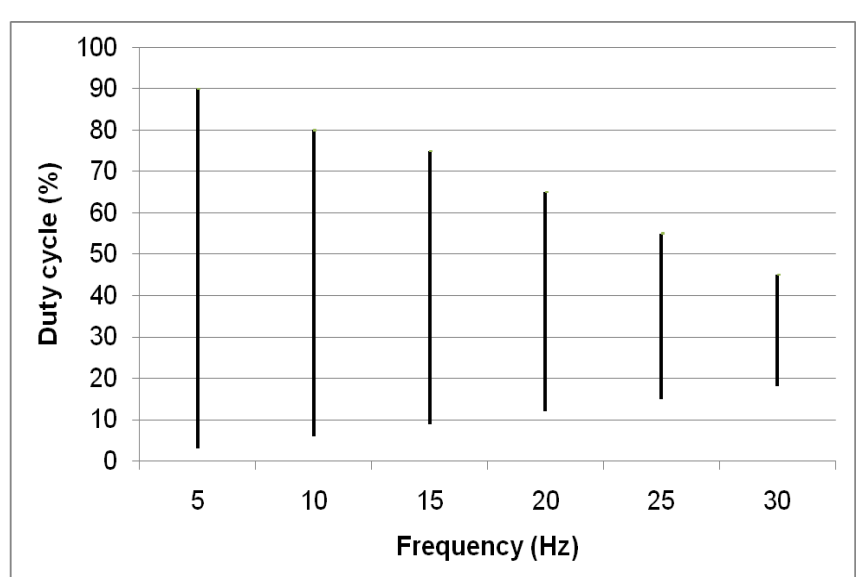

Fig - 29 Effective range of duty cycle corresponding to different frequencies

\section{CONCLUSIONS}

A nonlinear model of a low-cost pneumatic system using physical network modeling method has been developed using Matlab ${ }^{\circledR}$ Simscape toolbox. The pneumatic system consists of a double acting cylinder controlled by a pair of internally pilot $3 / 2$ direction control valves actuated by electric (on/off) solenoid. The predicted results have good agreement with the experimental measurements. The model response to the pulse width modulation signal is close to the actual valve response with the capability to express the valve dead zone phenomena. The system model is validated by experimental measurements and the valve model is also validated to use pulse width modulation (PWM) technique.

A parametric study has been developed to assist investigating the effective operating parameters to refine the piston position control. The parametric study shows that controlling the flow using meter-in control not only decreases the piston side pressure variation but also slows down the piston motion, which is not applicable for the high response applications. At supply pressure ranging from 5 to 8 bar, an orifice of 1 e- $6 \mathrm{~m} 2$ area and assuming 0.8 discharge coefficient, the piston side pressure variation is reduced by 
$80 \%$, while the time travel of the piston is increased by $130 \%$. Therefore, using the flow control (meter-in) is suitable for applications that use various supply pressure and don't require high actuator response. Reducing the pressure variation using meter-in control can help in more accurate control for the piston position. However, it affects the cylinder speed, which is not suitable for applications that need quick response.

In addition, having an almost constant backpressure (rod side pressure) by connecting an accumulator to the rod side chamber decreases the backpressure nonlinearity, hence making it easier to control the piston position. An accumulator with a small volume such as 1 liter can be used to reduce the backpressure variation with nearly $50 \%$.

Finally, the parametric study allows investigating the valve response to PWM input signal and shows the effective range of duty cycle corresponding to different frequencies and supply pressure. It can be concluded that the most suitable parameters for this valve are $20 \mathrm{~Hz}$ and duty cycle from 12 to $65 \%$.

Paragraph comes content here. Paragraph comes content here. Paragraph comes content here. Paragraph comes content here. Paragraph comes content here. Paragraph comes content here. Paragraph comes content here. Paragraph comes content here. Paragraph comes content here. Paragraph comes content here. Paragraph comes content here. Paragraph comes content here.

\section{REFERENCES}

[1]. Messina, A., N.I. Giannoccaro, and A. Gentile, Experimenting and modelling the dynamics of pneumatic actuators controlled by the pulse width modulation (PWM) technique. Mechatronics, 2005. 15(7): p. 859-881.

[2]. Blagojević, V. and M. Stojiljković, Mathematical and simulink model of the pneumatic system with bridging of the dual action cylinder chambers. Facta universitatis-series: Mechanical Engineering, 2007. 5(1): p. 23-31.

[3]. Rahmat, S., Non-linear modeling and cascade control of an industrial pneumatic actuator system. Australian Journal of Basic and Applied Sciences, 2011. 5(8): p. 465-477.

[4]. Dihovicni, D. and M. Medenica, Mathematical Modelling and Simulation of Pneumatic Systems. Advances in Computer Science and Engineering, 2011: p. 161-186.

[5]. Najjari, B., et al., Modelling and controller design of electro-pneumatic actuator based on PWM. IAES International Journal of Robotics and Automation (IJRA), 2012. 1(3): p. 125-136.

[6]. Servin, M. and V. Garcia, General Pressurization Model in Simscape. 2010.

[7]. CHIVU, C.-I., SIMULATION OF DOUBLE ACTING PNEUMATIC CYLINDER CONTROL. 2014.
[8]. Fischer, N.P., Simscape Modeling of a Custom ClosedVolume Tank. 2015.

[9]. ICHIM, I. and C. CHIVU, SIMULATION OF PNEUMATIC DIRECTIONAL VALVE. 2012.

[10]. Mathwork. Pneumatic Motor and Directional Control Valve. Available from: http://www.mathworks.com/help/physmod/simscape/e xamples/pneumatic-motor-and-directional-controlvalve.html.

[11]. Mathwork. Pneumatic Actuation Circuit. Available from:

http://www.mathworks.com/help/physmod/simscape/e xamples/pneumatic-actuation-circuit.html.

[12]. Thomas, M.B., G.P. Maul, and E. Jayawiyanto, A novel, low-cost pneumatic positioning system. Journal of manufacturing systems, 2005. 24(4): p. 377-387.

[13]. Lai, J.-Y., C.-H. Menq, and R. Singh, Accurate position control of a pneumatic actuator. Journal of dynamic systems, measurement, and control, 1990. 112(4): p. 734-739. 